\title{
Selenium-induced improvements in the ornamental value and salt stress resistance of Plectranthus scutellarioides (L.) R. Br.
}

\author{
Barbara Hawrylak-Nowak, Katarzyna Rubinowska*, Jolanta Molas, \\ Weronika Woch, Renata Matraszek-Gawron, Agnieszka Szczurowska
}

Department of Plant Physiology University of Life Sciences in Lublin Akademicka 15, 20-950 Lublin, Poland

\begin{abstract}
Ornamental plants growing in urban areas are often exposed to salt stress that negatively affects their decorative value. Enhancement of their salt resistance to retain a high decorative value despite salt stress has therefore high practical importance. In our study, the exposure of Plectranthus scutellarioides (L.) R. Br. to $\mathrm{NaCl}$-induced moderate $(40 \mathrm{mM})$ or severe salt stress $(80 \mathrm{mM})$ resulted in a number of stress responses including reduced growth parameters, decreased concentration of photosynthetic pigments, and an increase in the accumulation of anthocyanins and free proline. These changes were partially compensated for by the application of selenium $\left(5 \mu \mathrm{M}\right.$ as $\left.\mathrm{Na}_{2} \mathrm{SeO}_{4}\right)$ to the growth medium. However, the beneficial effect of selenium on the growth and physiological parameters of P. scutellarioides was manifested only at the moderate level of salt stress. Under the severe salt stress, the application of selenium was not able to alleviate the phytotoxic effect of $\mathrm{NaCl}$.
\end{abstract}

Key words: Plectranthus scutellarioides, salinity resistance, selenate, trace element

\section{INTRODUCTION}

Urbanisation-related activities result in unfavourable transformations of urban soils, whose physicochemical properties differ significantly from soil parameters in natural conditions. Salt stress is one of the most important factors exerting an adverse impact on the growth and development of urban plants. The problem of the harmful effects of urban stress, including excessive salinity, on greenery affects particularly roadside areas. Due to the application of de-icing salt onto communication routes, roadside soils are characterised by excessive accumulation of inorganic ions, mainly $\mathrm{Na}^{+}, \mathrm{Cl}^{-}$, and $\mathrm{Mg}^{2+}$ (Cunningham et al., 2008). Therefore, cultivation of ornamental plants in urban areas is somewhat difficult and does not always bring the expected results. An effect of the salinity of urban soils is the replacement of many salt-sensitive plant species from street-side lawns and green areas by resistant ruderal species (e.g. Atriplex nitens, Polygonum aviculare, Plantago major), which in turn diminishes the value of those areas (Wronocha and Gawroński, 2004). Most plant species are sensitive even to a relatively low level of salinity, which inhibits growth and reduces the number and surface area of leaves and roots; the reduction in the growth of aboveground organs is generally

*Corresponding author. 
greater than in the case of roots (Ramoliya et al., 2004; Munns and Tester, 2008). An excessive salinity level impairs water metabolism, mainly by reducing the water potential in the soil solution and thus limiting water availability, which consequently leads to disturbances in plant life processes. In turn, an excess of $\mathrm{Na}^{+}$and $\mathrm{Cl}^{-}$ions may lead to oxidative stress and contribute to the disruption of cell ionic homeostasis (Negrão et al., 2017).

The effect of salt stress on the growth rate and biomass of ornamental plants is not a sufficient determinant of the salinity tolerance in these species. A consequence of the toxic effect of excessive amounts of inorganic ions is the withering of leaf tips and margins. The presence of such changes should be considered in the analysis of the effect of salinity on ornamental plant species, as necrotic spots reduce their aesthetic value (Cassatini et al., 2012). The sensitivity of ornamental plants to salt stress varies greatly. Plectranthus scutellarioides (L.) R. Br. (syn. Coleus blumei Benth.) belongs to the Lamiaceae family and is highly prized for its vibrant and colourful foliage. This species is commonly grown in urban areas that face problems associated with excessive salinity of the substrate. However, the species is relatively sensitive to salt stress (Ibrahim et al., 1992).

Anumber of studies have indicated that increased concentrations of some mineral components in the substrate may have a beneficial impact on plants growing in excessive salinity conditions. A special role is ascribed to macronutrients such as calcium and potassium (Elkhatib et al., 2004). Additionally, exogenously applied trace elements (Banerjee and Roychoudhury, 2018), including silicon (Shahzad et al., 2013; Bosnic et al., 2018), iodine (Leyva et al., 2011), and selenium (Hawrylak-Nowak, 2009; Hawrylak-Nowak, 2015), can increase plant resistance to salinity. Although selenium is an essential micronutrient for humans and animals, its possibly indispensable role in plants has not yet been established (White, 2018). Nevertheless, a number of studies have demonstrated a positive effect of selenium on the growth of some plant species as well as a selenium-induced increase in plant antioxidant capacity and resistance to abiotic stress, e.g. UV radiation, drought, heavy metals, or salinity (Hawrylak-Nowak et al., 2018). The detailed mechanism of Se-mediated salt resistance has not been fully elucidated. Induction of the antioxidant machinery by selenium ions in some plant species grown under salinity has been reported in a majority of studies, but according to some other experiments this is not the entire effect of this element on the metabolism of salt-exposed plants. For instance, Jiang et al. (2017) indicated that application of selenite modified the cellular ultrastructure and mitigated NaCl-induced structural damage of chloroplasts, resulting in a more integrated internal lamella, thicker grana lamellae, and a more regular shape of the thylakoids than in the plants treated with $\mathrm{NaCl}$ alone.

There have been relatively few investigations of the impact of salinity on ornamental plants, and the effect of trace elements on these species has so far not been sufficiently documented. Given the positive effect of selenium on the resistance of some crop species to salt stress, we propose a hypothesis that salt resistance in ornamental plant species may increase as an effect of selenium supplementation. Hence, the aim of this study was to assess the possibility of enhancing the resistance and ornamental value of $P$. scutellarioides growing under $\mathrm{NaCl}$-induced salt stress by the application of exogenous selenium. For this purpose, we estimated some indicators of stress resistance (plant growth parameters, selected parameters of chlorophyll $a$ fluorescence, the level of free proline) and indicators of the ornamental value of the leaves (leaf area, concentrations of chlorophylls, carotenoids, and anthocyanins) of this species grown under varied experimental conditions.

\section{MATERIAL AND METHODS}

\section{Plant material and growing conditions}

The experiment was carried out in hydroponic cultures. It consisted in assessing the effect of applying selenium ( $5 \mu \mathrm{M} \mathrm{Se}, \mathrm{Na}_{2} \mathrm{SeO}_{4}$ ) to a nutrient solution containing $\mathrm{NaCl}$ (40 or 80 $\mathrm{mM}$ ) on the growth, decorative value, and selected morphological and physiological parameters of Plectranthus scutellarioides (L.) R. Br.

$P$. scutellarioides seeds (Legutko Company, mix of colours) were placed on moistened filter paper in Petri dishes and left to germinate for 14 days. Next, the seedlings at the stage of 2 true leaves were transferred to plastic containers filled with garden soil for sowing seeds and pricking out seedlings. The plants grew for another 3 weeks in an air-conditioned phytotron in optimal conditions $\left(25 / 20^{\circ} \mathrm{C}, 14 / 10 \mathrm{~h}\right.$, day/night). After that time, plants with approximately 6 true leaves and with a similar intensity and type of pigmentation were selected for the experiment. Soil was thoroughly removed from the root system and two plants were 
placed in each glass jar $(1 \mathrm{~L})$ filled with Hoagland nutrient solution No. 2. The $\mathrm{pH}$ of the medium was adjusted to $\mathrm{pH}=6.0$ with diluted $\mathrm{NaOH}$; next, the medium was diversified in terms of the concentration of $\mathrm{NaCl}$ and selenium. Salinity levels were selected on the basis of preliminary experiments and observation of the morphology and pigmentation of plants under different salinity conditions. The selenium concentration chosen was that found effective in salt stress mitigation in other $\mathrm{NaCl}$-stressed plant species tested previously under hydroponic conditions. The experiment consisted of the following five experimental treatments:

- control $(0 \mathrm{NaCl} / 0 \mathrm{Se})$,

- $40 \mathrm{mM} \mathrm{NaCl}$ (moderate salt stress),

- $40 \mathrm{mM} \mathrm{NaCl}+5 \mu \mathrm{M}$ Se (selenium

supplementation under moderate salt stress),

- $80 \mathrm{mM} \mathrm{NaCl}$ (severe salt stress),

- $80 \mathrm{mM} \mathrm{NaCl}+5 \mu \mathrm{M}$ Se (selenium

supplementation under severe salt stress).

The plants were grown in hydroponic cultures under controlled conditions in the phytotron chamber (Sanyo MRL 350 HT, Japan). Photosynthetic photon flux density (PPFD) was $200 \mu \mathrm{mol} \mathrm{m}^{-2} \mathrm{~s}^{-1}$ at the level of plant tops, a $14 / 10 \mathrm{~h}$ (day/night) photoperiod, a temperature of $25 / 20^{\circ} \mathrm{C}$ (day/night), and $60 \%$ relative humidity. After 14 days of plant growth in varied experimental conditions, the biometric parameters (plant biomass, root system length) and physiological parameters (selected parameters of chlorophyll $a$ fluorescence, free proline concentration) were determined. Additionally, changes in plant morphology and ornamental value (leaf area, concentration of pigments in leaves) induced by the experimental conditions were assessed. The experiment involved five treatments and four replications (jars) per each treatment. Two plants were placed in each jar, which gives eight plants in each experimental treatment.

To ensure the reliability of the results, two independent experiments under the same controlled conditions were performed: the first one in March 2017 and the second in July 2017.

\section{Analysis of growth parameters}

The shoots and roots of plants from each jar were harvested separately and washed twice with distilled water. Some growth parameters such as fresh weight (FW), leaf area (LA), and root length (RL) were measured. For LA determination, fresh second true leaves were scanned using a CI-202
Laser Leaf Area Meter (CID Bio-Science, USA). The length of the root system was measured with a ruler.

\section{Determination of pigment content}

The concentration of photosynthetic pigments was determined in FW of the second leaves from the base of the plant by homogenizing fresh samples with an $80 \%(v / v)$ acetone/water solution according to the method of Lichtenthaler and Wellburn (1983). The absorbance of the resulting extracts was measured at 646,663 , and $470 \mathrm{~nm}$ for chl $a$, chl $b$ and carotenoids, respectively. The concentration of the pigments was calculated using equations proposed by Lichtenthaler and Wellburn (1983).

Total anthocyanin content was determined according to the method described in detail previously (Hawrylak-Nowak, 2008). Briefly, anthocyanins were extracted from the second leaves from the base of the plant by sample maceration in a methanol/ $\mathrm{HCl}(99: 1, v / v)$ solution. The extracts were clarified by centrifugation at $10,000 \mathrm{~g}$. Quantification of anthocyanins was done spectrophotometrically at $527 \mathrm{~nm}$ and $652 \mathrm{~nm}$, and calculated using the molar absorbance coefficient for cyanidin 3-glycoside $\left(\varepsilon=29,600 \mathrm{M}^{-1} \mathrm{~cm}^{-1}\right)$.

\section{Determination of selected parameters of chlorophyll a fluorescence}

The determined parameters of chlorophyll $a$ fluorescence included the minimum $\left(\mathrm{F}_{0}\right)$ and maximum $\left(\mathrm{F}_{\mathrm{m}}\right)$ possible value for fluorescence as well as the maximum quantum yield of photosystem II (PS II; $F_{v} / F_{m}$, where $F_{v}=F_{m}$ $\left.\mathrm{F}_{0}\right)$. The measurements were performed on the second leaves from the base using a Handy PEA chlorophyll fluorimeter (Hansatech Instruments, Japan). The $P$. cutellarioides leaves were adapted to darkness for $15 \mathrm{~min}$. before measurements by attaching special light-exclusion clips.

\section{Determination of free proline content}

The level of proline was determined according to the standard method developed by Bates et al. (1973). After homogenization of leaf samples $(0.5 \mathrm{~g})$ in $3 \%$ sulphosalicylic acid and subsequent filtration, the plant extract, acid ninhydrin, and glacial acetic acid $(1: 1: 1)$ were incubated at $100^{\circ} \mathrm{C}$ for $1 \mathrm{~h}$. The reaction was terminated in an ice bath. Then, the reaction mixture was extracted with toluene and the chromophore-containing toluene phase was collected. The concentration of proline was measured spectrophotometrically at $520 \mathrm{~nm}$ 
using toluene as a blank and calculated as $\mu \mathrm{g} \mathrm{g}^{-1} \mathrm{FW}$ against standard proline.

\section{Statistical analysis}

The values in the figures and tables represent the means $( \pm \mathrm{SD})$ from two independent experiments. All the data were subjected to one-way analysis of variance (ANOVA) with Tukey's post-hoc test at $p<0.05$.

\section{RESULTS}

The growth of $P$. scutellarioides was affected by the addition of $\mathrm{NaCl}$ to the growth medium. In the presence of $40 \mathrm{mM} \mathrm{NaCl}$, shoot and root biomass accumulation was reduced by $57 \%$ and $61 \%$, respectively, whereas in the presence of $80 \mathrm{mM}$ $\mathrm{NaCl}$, the reduction in shoot and root biomass was $66 \%$ and $71 \%$, respectively (Fig. 1A, 1B). However, FW of both organs of the plants growing in the nutrient solutions containing 40 and $80 \mathrm{mM} \mathrm{NaCl}$ was similar.

The application of $5 \mu \mathrm{M}$ Se to the salt-containing medium partially mitigated the adverse effect of salt stress on biomass accumulation in the plants, but only at the moderate level of salinity $(40 \mathrm{mM}$ $\mathrm{NaCl}$ ). The $\mathrm{FW}$ of aboveground organs and roots in the plants growing at the moderate salinity level with the addition of selenium was about $59 \%$ and $52 \%$ higher, respectively, than in the plants growing without selenium. The addition of selenium to the medium containing $80 \mathrm{mM} \mathrm{NaCl}$ did not alleviate the negative effect of salinity on biomass accumulation (Fig. 1A, 1B). However, in all the cases, the leaves did not exhibit symptoms of necrosis throughout the experiment (Fig. 2).

The length of the root system was not reduced in the plants growing at $40 \mathrm{mM} \mathrm{NaCl}$, whereas a $38 \%$ reduction was noted in the plants treated with $80 \mathrm{mM} \mathrm{NaCl}$ (Fig. 1C). The application of selenium to the medium containing $40 \mathrm{mM} \mathrm{NaCl}$ caused inhibition of root system elongation. The application of selenium to the medium containing $80 \mathrm{mM} \mathrm{NaCl}$ did not exert an effect on the length of the root system (Fig. 1C).

The application of $40 \mathrm{mM}$ and $80 \mathrm{mM} \mathrm{NaCl}$ caused a similar, $61-64 \%$, reduction in LA of the second leaf (Fig. 1D), compared with the control. The addition of selenium to the growth medium containing $40 \mathrm{mM} \mathrm{NaCl}$ alleviated, by about $43 \%$, the negative effect of salt stress on the growth of leaves. Such an effect was not observed in the plants growing under the severe stress $(80 \mathrm{mM}$ $\mathrm{NaCl})$ conditions.

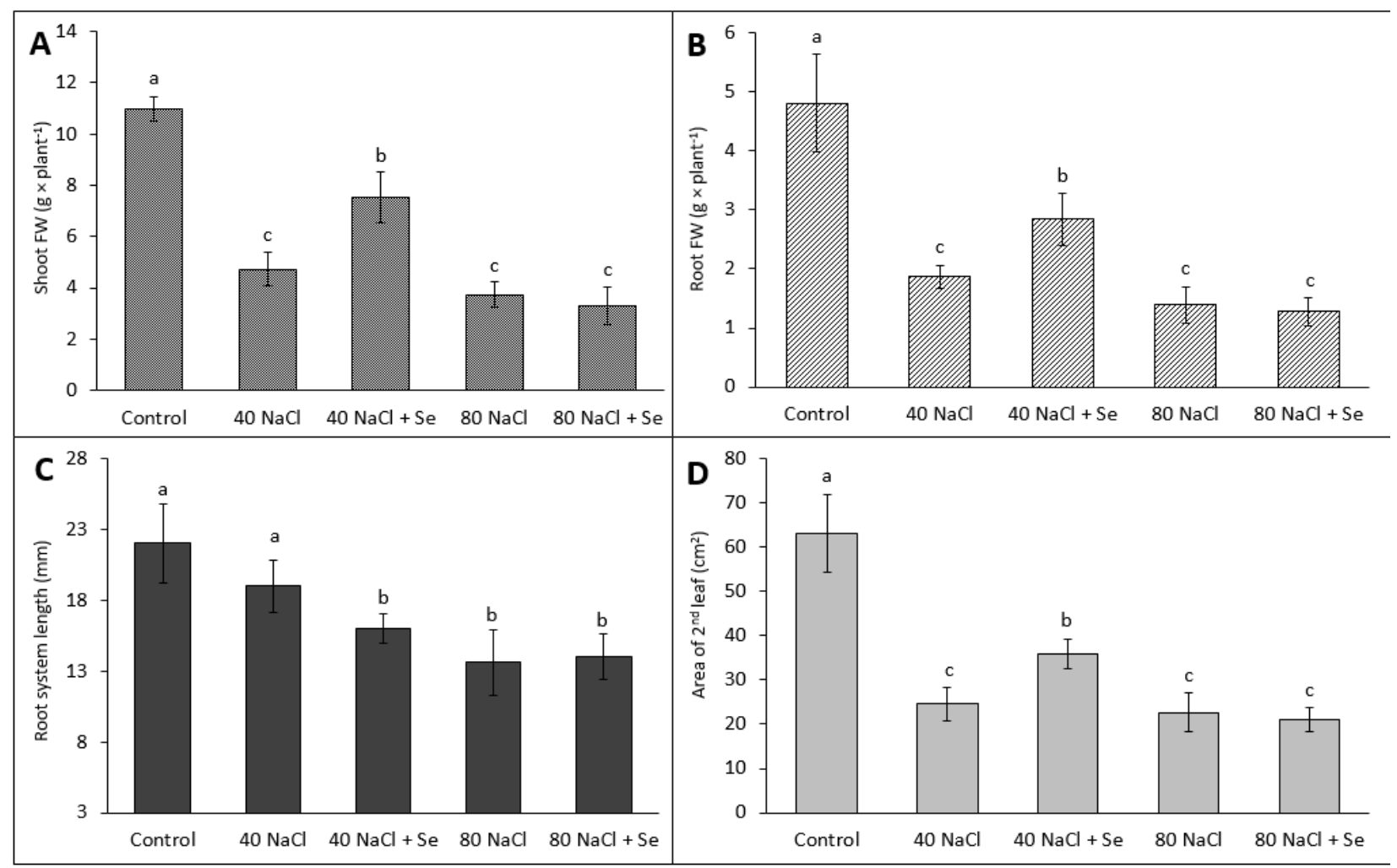

Figure 1. Effect of Se application on shoot FW (A), root FW (B), root system length (C), and leaf area of second leaf (D) of $P$. scutellarioides grown at different levels of $\mathrm{NaCl}$-induced salt stress. Means $( \pm \mathrm{SD}, \mathrm{N}=12)$ with different letters above the bars are significantly different $(p<0.05)$ according to Tukey's LSD test 
The concentrations of chlorophyll $a$ and $b$ in the leaves of the plants grown under the conditions of medium and severe salt stress were reduced by $32-35 \%$ and $29-40 \%$, respectively. Similarly, the carotenoid concentration was reduced by $30-$ $34 \%$ (Fig. 3A, 3B). The application of selenium to the medium containing $40 \mathrm{mM} \mathrm{NaCl}$ caused an increase in the concentration of the chlorophylls (by 27\%) and carotenoids (by 31\%), in comparison with the plants cultivated under the moderate salt stress. However, no such effect was found after the application of selenium at the higher salinity level (Fig. 3A, 3B). The ratio of chlorophyll $a$ to chlorophyll $b$ in the control plants and in those

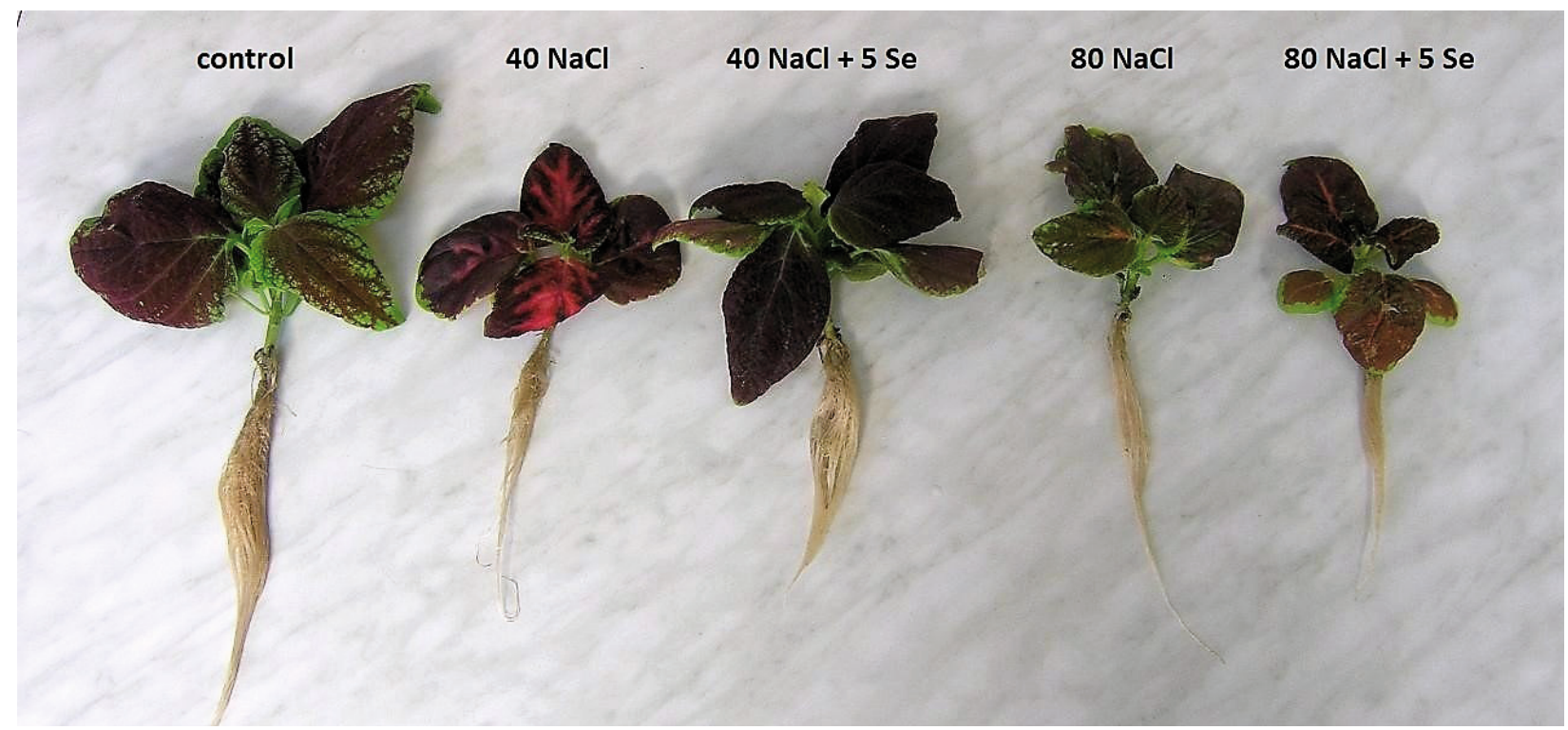

Figure 2. Phenotypic appearance of $P$. scutellarioides grown at different levels of $\mathrm{NaCl}$-induced salt stress with or without selenium

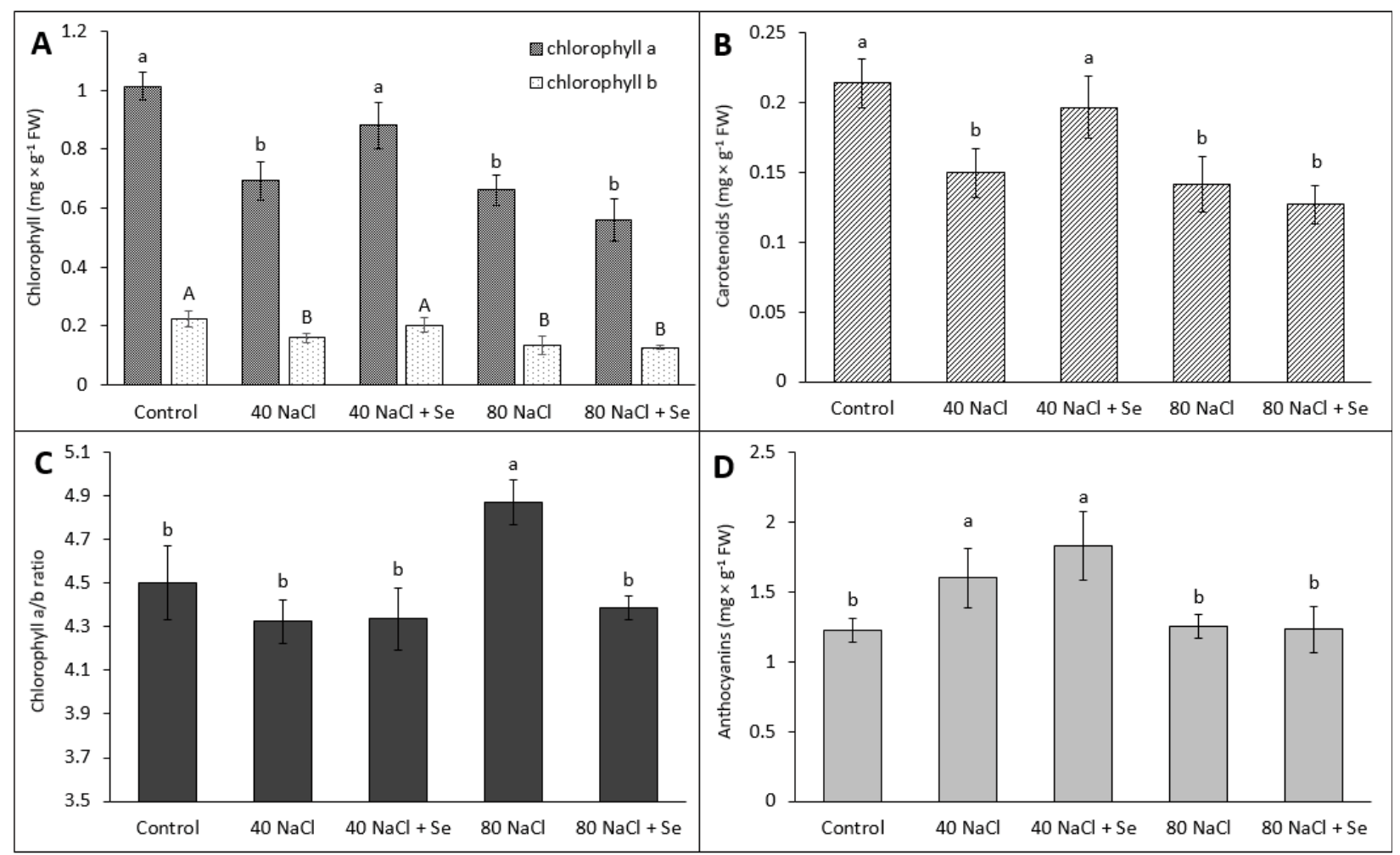

Figure 3. Effect of Se application on the concentration of photosynthetic pigments (A, B), chlorophyll a/b ratio (C), and anthocyanin content (D) in the leaves of $P$. scutellarioides grown at different levels of NaCl-induced salt stress. Means $( \pm \mathrm{SD}, \mathrm{N}=6)$ with different letters above the bars are significantly different $(p<0.05)$ according to Tukey's LSD test 


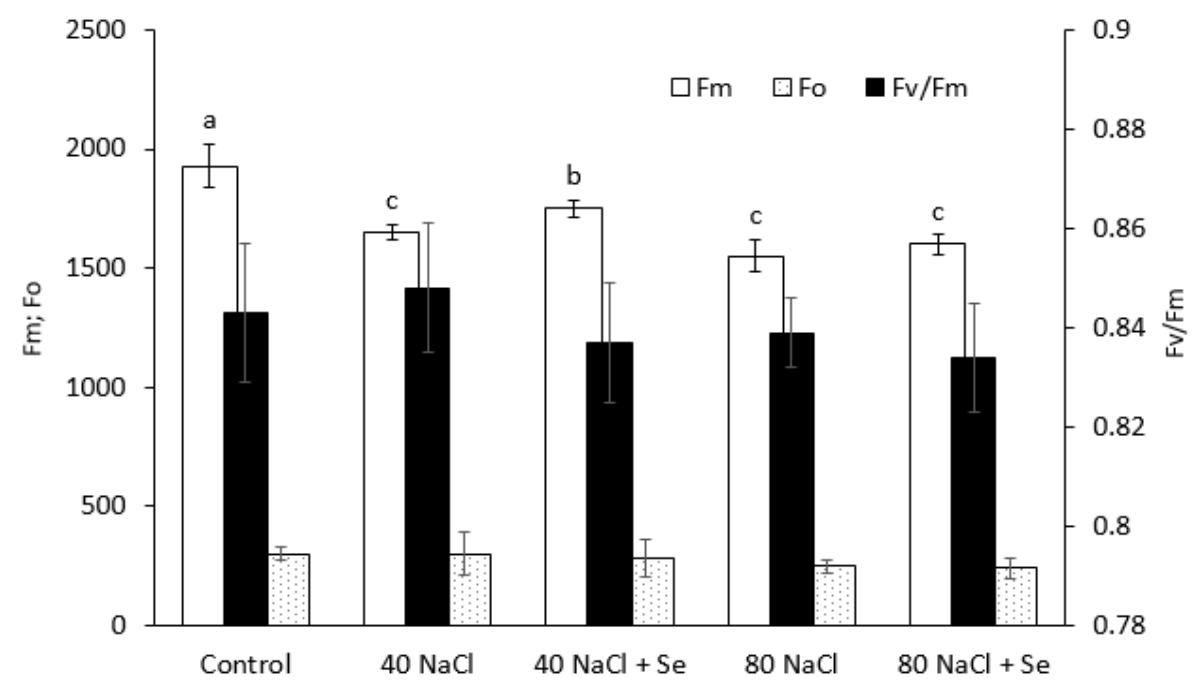

Figure 4. Effect of Se application on the selected parameters of chlorophyll $a$ fluorescence in the leaves of $P$. scutellarioides grown at different levels of $\mathrm{NaCl}$-induced salt stress. Means $( \pm \mathrm{SD}, \mathrm{N}=12)$ with different letters above the bars are significantly different $(p<0.05)$ according to Tukey's LSD test. Means without letters are not significantly different

growing in the presence of $40 \mathrm{mM} \mathrm{NaCl}, 40 \mathrm{mM}$ $\mathrm{NaCl}+\mathrm{Se}$, and $80 \mathrm{mM} \mathrm{NaCl}+\mathrm{Se}$ was in the range of 4.3-4.5. An increase in this parameter (up to 4.9) was noted only in the plants treated with $80 \mathrm{mM}$ $\mathrm{NaCl}$ (Fig. 3C).

The concentration of anthocyanin pigments in the leaves of the plants growing in the substrate containing $40 \mathrm{mM} \mathrm{NaCl}$ was by $31 \%$ higher than that in the control plants (Fig. 3D). No changes in their concentration were found in the plants cultivated in the substrate with the addition of $80 \mathrm{mM} \mathrm{NaCl}$. The application of selenium to the substrate containing either $40 \mathrm{mM}$ or $80 \mathrm{mM} \mathrm{NaCl}$ did not result in an increase in the anthocyanin content.

The salt stress and selenium supplementation exerted no significant effect on the level of the

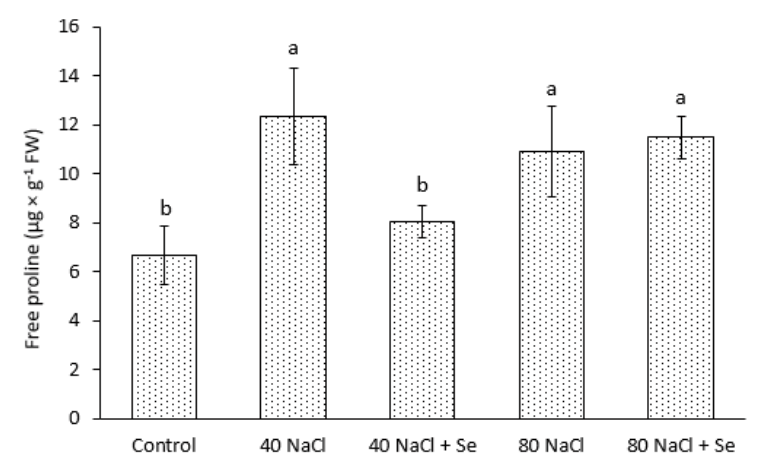

Figure 5. Effect of Se application on free proline accumulation in the leaves of $P$. scutellarioides grown at different levels of $\mathrm{NaCl}$-induced salt stress. Means $( \pm \mathrm{SD}, \mathrm{N}=6$ ) with different letters above the bars are significantly different $(p<0.05)$ according to Tukey's LSD test minimum fluorescence $\left(\mathrm{F}_{0}\right)$ and the $\mathrm{F}_{\mathrm{v}} / \mathrm{F}_{\mathrm{m}}$ value. In turn, the maximum fluorescence $\left(\mathrm{F}_{\mathrm{m}}\right)$ was significantly lower in the leaves of the plants growing under the salt stress conditions than in the control medium (Fig. 4). The application of selenium to the substrate containing $40 \mathrm{mM} \mathrm{NaCl}$ caused a significant, but slight, increase in $\mathrm{F}_{\mathrm{m}}$ compared to the plants growing in the presence of $\mathrm{NaCl}$ only.

An increased level of free proline in the leaves was noted in the plants affected by either level of salt stress, compared with the control combination. The level of this amino acid was by $85 \%$ and $64 \%$ higher in the presence of 40 and $80 \mathrm{mM} \mathrm{NaCl}$, respectively. After the application of selenium, the concentration of free proline declined by $35 \%$ in the plants growing in the presence of $40 \mathrm{mM} \mathrm{NaCl}$. No effect on the accumulation of this amino acid was noted after the application of selenium to the substrate supplemented with $80 \mathrm{mM} \mathrm{NaCl}$ (Fig. 5).

\section{DISCUSSION}

One of the first responses of plants to salt stress is limitation of their growth rate, which is mainly caused by the osmotic activity of salt in the rhizosphere leading to reduced water supply in aboveground parts. Excessive concentrations of salts can inhibit root growth, and toxic amounts of $\mathrm{Na}^{+}$and $\mathrm{Cl}^{-}$ions impair the uptake of essential elements (Munns and Tester, 2008). Salt stress leads to leaf browning and yellowing as well as disturbances in flowering; hence, ornamental plants lose their decorative value (Cassaniti et al., 
2012; Matraszek et al., 2015). Reduction of growth and deterioration of the ornamental value were also found in the P. scutellarioides plants analysed in the present study. In the salt stress conditions, the plants were characterised by lower root and shoot biomass, smaller lamina surface area, and poorer pigmentation, which was reflected in a decline in the concentration of photosynthetic pigments in comparison with the control plants. In turn, there were no necrotic lesions on the P. scutellarioides leaf blades, which was most probably associated with the relatively short exposure of the plants to salt stress (14 days). In the present study, the moderate salinity $(40 \mathrm{mM} \mathrm{NaCl})$ did not disturb the elongation of the root system, whereas a significant reduction in its length was noted in the conditions of the severe salt stress. It has been shown that salt stress inhibits the cell cycle and cell elongation, thereby contributing to the inhibition of taproot growth (Wang et al., 2009).

The reduction in the concentration of photosynthetic pigments is one of the important causes of the decline in the intensity of photosynthesis under salinity (Sudhir and Murthy, 2004). The major causes of the reduction in chlorophyll levels in salt stress conditions include inhibition of chlorophyll biosynthesis associated with the reduction in the synthesis of 5-aminolevulinic acid, i.e. a chlorophyll precursor, and the increase in the activity of chlorophyllase, i.e. an enzyme involved in the chlorophyll biodegradation process (Santos, 2004). In turn, the salinity-induced reduction in the concentration of carotenoids may be related to $\beta$-carotene degradation and formation of zeaxanthin (Hawrylak-Nowak, 2009). Moreover, enhanced accumulation of anthocyanin pigments occurs as a result of salt stress (Ery1lmaz, 2006), which was also noted in the present study, but only under the moderate salinity. Under stress, anthocyanins can be involved in, for example, quenching of reactive oxygen species, photoprotection, and stress signalling (Kovinich et al., 2015). Since anthocyanins are osmotically active compounds, their enhanced accumulation may increase salt stress tolerance through increased osmotic potential. Anthocyanins can also protect cells from ion-induced oxidative damage by their ability to bind toxic ions and thereby lowering their toxicity to cytoplasmic structures (Wahid and Ghazanfar, 2006).

The $\mathrm{F}_{\mathrm{v}} / \mathrm{F}_{\mathrm{m}}$ value for the leaves of non-stressed plants is highly consistent, oscillating around the value of $\sim 0.83$, and correlates with the maximum quantum yield of photosynthesis (Murchie and Lawson, 2013). In our study, the level of the maximum fluorescence $\left(\mathrm{F}_{\mathrm{m}}\right)$ was the only chlorophyll fluorescence parameter reduced by salinity, whereas the minimum fluorescence $\left(\mathrm{F}_{0}\right)$ and the maximum quantum yield of photosystem PS II $\left(\mathrm{F}_{\mathrm{v}} / \mathrm{F}_{\mathrm{m}}\right)$ did not vary significantly even at the severe stress. The reduced $F_{m}$ value indicates a decline in the number of excitable PS II reaction centres and a potential decrease in PS II efficiency (Murchie and Lawson, 2013). Salt stress can reduce PS II activity, e.g. due to the deleterious effects of the oxygen-evolving complex (OEC) on the Mn cluster or the dissociation of plastocyanin/cytochrome c553. Therefore, the whole-chain electron transport is affected at excessive salinity (Stirbet et al., 2018). The present study demonstrated that the application of selenium to the salt-containing substrate stimulated the growth of shoots and roots; however, the positive effect of this element was only noted at the moderate salinity level $(40 \mathrm{mM} \mathrm{NaCl})$. The FW of the aboveground parts in the presence of selenium was by over $50 \%$ higher than that of the plants growing on the substrate supplemented with $40 \mathrm{mM} \mathrm{NaCl}$ only. The addition of selenium to this substrate exerted also a positive effect on the concentration of photosynthetic pigments. Similar results had been reported in a study conducted by Hawrylak-Nowak (2009), where the application of selenium partly mitigated the adverse effect of salinity on cucumber plants via enhancement of plant growth and accumulation of photosynthetic pigments. Investigations conducted by Kong et al. (2005) demonstrated that the presence of selenium increased the tolerance of sorrel to salt stress, which was associated with the improvement of the integrity of chloroplast cell membranes. In turn, Diao et al. (2014) suggest that selenium can mitigate salinity-induced stress by regulating antioxidant mechanisms in chloroplasts, which is related to an increase in PS II photochemical efficiency. We, too, noted a beneficial effect of selenium on the photosynthesis process, the disturbances in which were associated with a decline in the maximum fluorescence $\left(\mathrm{F}_{\mathrm{m}}\right)$. At the moderate salinity stress, the $\mathrm{F}_{\mathrm{m}}$ value significantly increased after the introduction of selenium to the growth medium.

The P. scutellarioides plants treated with $80 \mathrm{mM}$ $\mathrm{NaCl}$ did not respond positively to the presence of selenium in the nutrient medium. In those conditions, there was no beneficial effect of this element on either the biomass of individual organs or the concentration of pigments in the leaves. 
Similarly, the morphology and decorative value of the selenium-supplemented plants did not differ significantly from those of the plants treated with $80 \mathrm{mM} \mathrm{NaCl}$ only. Hence, it seems that selenium loses its positive properties in severe salt stress conditions, since such high salinity may exceed the level of plant tolerance, and supplementation of plants with this element is probably no longer able to mitigate the toxic effect of $\mathrm{NaCl}$.

The necessity to maintain osmotic and ionic balance in cells leads to the synthesis of various types of osmoprotectants, e.g. proline. Proline accumulation in response to osmotic stress has been widely reported; it may play a role in stress resistance within the cell, which is of great interest to those studying stresses in plants (Zhu, 2001). The present study demonstrated that the proline concentration in P. scutellarioides leaves under the moderate and severe salinity levels increased significantly, compared with the control plants. In contrast, the application of selenium to the medium containing $40 \mathrm{mM} \mathrm{NaCl}$ reduced the level of free proline, relative to the plants growing at moderate salinity only. The application of selenium under the severe salt stress did not exert an effect on the concentration of this amino acid. It can therefore be concluded that salinity induces proline accumulation in $P$. scutellarioides, but selenium modifies the level of this amino acid only at moderate $\mathrm{NaCl}$ concentrations. Contrasting results had been reported by Hawrylak-Nowak (2009) in the investigations conducted on cucumber plants. It was shown that cucumber plants growing in a salt-containing nutrient solution exhibited lower amounts of proline than the control plants. In turn, enrichment of the substrate with selenium contributed to an increase in the concentration of this amino acid, compared with plants treated only with $\mathrm{NaCl}$. Therefore, it seems that selenium can modify the accumulation of free proline in the leaves of plants grown under salinity, yet the response is species-specific, as in the case of salt stress only. Although the causes of seleniuminduced fluctuations in the proline content have not been elucidated to date, it is suggested that selenium may influence the activity of enzymes involved in proline metabolism, i.e. glutamyl kinase and proline oxidase (Khan et al., 2015).

\section{CONCLUSIONS}

1. Selenium supplementation under moderate salt stress can, at least partially, alleviate the adverse effect of salinity on $P$. scutellarioides, thereby enhancing its ornamental value and resistance to stress conditions.

2. Under severe salt stress, selenium has no significant effect on the growth and ornamental qualities of this species.

3. The application of selenium at moderate salinity levels may be an effective way to mitigate the unfavourable effects of salt stress on P. scutellarioides cultivated in urban areas characterised by increased risk of excessive accumulation of salts in the substrate.

\section{FUNDING}

This research was financially supported by the statutory funds from the Polish Ministry of Science and Higher Education (OKA/DS/3, Department of Plant Physiology, University of Life Sciences in Lublin).

\section{AUTHOR CONTRIBUTIONS}

B.H.N. - developed the concept, designed the experiment and wrote the paper; K.R., J.M., W.W., R.M.G., A.S. - participated in the laboratory work, data collection and interpretation, discussion as well as drafting the manuscript. All the authors read and approved the final manuscript.

\section{CONFLICT OF INTEREST}

The authors declare no conflict of interest.

\section{REFERENCES}

Banerjee A., Roychoudhury A., 2018. Role of beneficial trace elements in salt stress tolerance of plants. In: Plant Nutrients and Abiotic Stress Tolerance. M. Hasanuzzaman, M. Fujita, H. Oku, K. Nahar and B. Hawrylak-Nowak (Eds), Springer, Singapore, 377-390.

Bates L., Waldren R., Teare J., 1973. Rapid determination of free proline for water stress studies. Plant Soil 39, 205-207.

Bosnic P., Bosnic D., Jasnic J., Nikolic M., 2018. Silicon mediates sodium transport and partitioning in maize under moderate salt stress. Environ. Exp. Bot. 155, 681-687.

Cassaniti C., Romano D., Flowers T.J., 2012. The response of ornamental plants to saline irrigation water. In: Irrigation - Water Management, Pollution and Alternative Strategies. I. Garcia-Garizabal (Ed.), IntechOpen, London, UK, 131-158.

Cunningham M.A., Snyder E., Yonkin D., Ross M., ELSEN T., 2008. Accumulation of deicing salts in soils in an urban environment. Urban Ecosyst. 11, $1-31$. 
Diao M., Ma L., Wang J., Cui J., Fu A., LiU H., 2014. Selenium promotes the growth and photosynthesis of tomato seedlings under salt stress by enhancing chloroplast antioxidant defence system. J. Plant Growth Regul. 33, 671-682.

Elkhatib H.A., Elkhatib E.A., Allah A.M.K., El-Sharkawy A.M., 2004. Yield response of salt stressed potato to potassium fertilization: a preliminary mathematical model. J. Plant Nutr. 27, 111-122.

Eryilmaz F., 2006. The relationships between salt stress and anthocyanin content in higher plants. Biotechnol. Biotec. Eq. 20, 47-52.

HaWryLAK-NowAK B., 2008. Changes in anthocyanin content as indicator of maize sensitivity to selenium. J. Plant Nutr. 31, 1232-1242.

HAWrYLAK-NowAK B., 2009. Beneficial effects of exogenous selenium in cucumber seedlings subjected to salt stress. Biol. Trace Elem. Res. 132, 259-269.

Hawrylak-NowaK B., 2015. Selenite is more efficient than selenate in alleviation of salt stress in lettuce plants. Acta Biol. Cracov., Ser. Bot. 57, 49-54.

HaWrylak-NowaKB.,HaSANUZZAmanM., MatraszeK -GaWron R., 2018. Mechanisms of seleniuminduced enhancement of abiotic stress tolerance in plants. In: Plant Nutrients and Abiotic Stress Tolerance. M. Hasanuzzaman, M. Fujita, H. Oku, K. Nahar and B. Hawrylak-Nowak (Eds), Springer, Singapore, 269-295.

Ibrahim K.M., Collins J.C., Collin H.A., 1992. Characterization of progeny of Coleus blumei following an in vitro selection for salt tolerance. Plant Cell Tissue Organ Cult. 28, 139-145.

Jiang C., Zu C., Lu D., Zheng Q., Shen J., Wang H., eT AL., (2017) Effect of exogenous selenium supply on photosynthesis, $\mathrm{Na}^{+}$accumulation and antioxidative capacity of maize (Zea mays L.) under salinity stress. Sci. Rep. 7, 42039.

Khan M.I.R., Nazir F., Asgher M., Per T.S., Khan N.A., 2015. Selenium and sulfur influence ethylene formation and alleviate cadmium-induced oxidative stress by improving proline and glutathione production in wheat. J. Plant Physiol. 173, 9-18.

Kong L., Wang M., Bi D., 2005. Selenium modulates the activities of antioxidant enzymes, osmotic homeostasis and promotes the growth of sorrel seedlings under salt stress. Plant Growth Regul. 45, 155-163.

Kovinich N., Kayanja G., Chanoca A., Otegui M.S., Grotewold E., 2015. Abiotic stresses induce different localizations of anthocyanins in Arabidopsis. Plant Signal. Behav. 10, 7.

Leyva R., SÁnchez-Rodríguez E., Ríos J.J., RubioWilhelmi M.M., Romero L., Ruiz J.M., ET AL., 2011. Beneficial effects of exogenous iodine in lettuce plants subjected to salinity stress. Plant Sci. 181, 195-202.
Lichtenthaler H.K., Wellburn A.R., 1983. Determinations of total carotenoids and chlorophylls $\mathrm{a}$ and $\mathrm{b}$ of leaf extracts in different solvents. Biochem. Soc. Trans. 603, 591-592.

Matraszek R., Hawrylak-Nowak B., Chwil M., 2015. Protein hydrolysate as a component of salinized soil in the cultivation of Ageratum houstonianum Mill. (Asteraceae). Acta Agrobot. 68, 247-253.

Munns R., Tester M., 2008. Mechanisms of salinity tolerance. Annu. Rev. Plant Biol. 59, 651681.

Murchie E.H., Lawson T., 2013. Chlorophyll fluorescence analysis: a guide to good practice and understanding some new applications. J. Exp. Bot. 64, 3983-3998.

Negrão S., Schmöckel S.M., Tester M., 2017. Evaluating physiological responses of plants to salinity stress. Ann. Bot. 119, 1-11.

Ramoliya P.J., Patel H.M., Pandey A.N., 2004. Effect of salinisation of soil on growth and macro- and micro-nutrient accumulation in seedlings of Acacia catechu (Mimosaceae). Ann. Appl. Biol. 144, 321332.

Santos C.C., 2004. Regulation of chlorophyll biosynthesis and degradation by salt stress in sunflower leaves. Sci. Hortic. 103, 93-99.

Shahzad M., Zörb C., Geilfus C.M., Mühling K.H., 2013. Apoplastic $\mathrm{Na}^{+}$in Vicia faba leaves rises after short-term salt stress and is remedied by silicon. J. Agron. Crop Sci. 199, 161-170.

Stirbet A., LazÁr D., KromdiJK J., Govindjee, 2018. Chlorophyll a fluorescence induction: Can just a one-second measurement be used to quantify abiotic stress responses? Photosynthetica 56, 86-104.

SudHIR P., MuRThy S.D.S., 2004. Effects of salt stress on basic processes of photosynthesis. Photosynthetica 42, 481-486.

Wahid A., Ghazanfar A., 2006. Possible involvement of some secondary metabolites in salt tolerance of sugarcane. J. Plant Physiol. 163, 723-730.

WANG Y., Li K., LI X., 2009. Auxin redistribution modulates plastic development of root system architecture under salt stress in Arabidopsis thaliana. J. Plant Physiol. 166, 1637-1645.

White P.J., 2018. Selenium metabolism in plants. Biochim. Biophys. Acta Gen. Subj. 1862, 2333-2342.

Wrochna M., Gawroński S.W., 2004. Ocena przydatności roślin ozdobnych z rodziny komosowatych i szarłatowatych do uprawy na stanowiskach zasolonych [Evaluation of the usefulness of ornamental plants from the family Chenopodiaceae and Amaranthaceae for cultivation in saline areas]. Roczn. AR w Poznaniu, CCCLVI, Ogrodnictwo 37, 233-238 [in Polish].

Zhu J.K., 2001. Plant salt tolerance. Trends Plant Sci. 6, 66-71.

Received December 20, 2018; accepted April 4, 2019 